\title{
Minimally Invasive Anterior Decompression Technique without Instrumented Fusion for Huge Ossification of the Posterior Longitudinal Ligament in the Thoracic Spine : Technical Note And Literature Review
}

\author{
Jae Won Yu, Sang-O Yun, ${ }^{1}$ Chang-Sheng Hsieh, ${ }^{2}$ Sang-Ho Lee ${ }^{3}$ \\ Department of Neurosurgery, Spine Health Wooridul Hospital, Busan, Korea \\ Department of Orthopedics, ${ }^{2}$ Tai Shin Hospital, Taichung, Taiwan \\ Department of Neurosurgery, ${ }^{3}$ Spine Health Wooridul Hospital Gangnam, Seoul, Korea
}

Notice of Retraction: This article has been retracted by the author. This article involves in conflicts in authorship. We apologize to the readership of Journal of Korean Neurosurgical Society. 